\title{
Dos palacios del Barroco tardío en Marruecos: las legaciones diplomáticas de España en Larache y Tánger $^{1}$
}

\begin{abstract}
Antonio Bravo Nieto
Escuela Nacional de Arquitectura de Tetuán

RESUMEN: Un interesante y desconocido capítulo de la persistencia de las formas barrocas en la ar- العر ائش) quitectura española del siglo XVIII se encuentra en dos ciudades de Marruecos: Larache Al Araish) y Tánger (طن - Tanja). En estas capitales, el rey Carlos III ordenó construir dos edificios que funcionaron como legaciones diplomáticas ante el Sultán. En ellos se mantiene todavía un cierto carácter manierista, aunque situado ya en una cronología del barroco más tardío. Los proyectos fueron realizados por los arquitectos Juan Fernández y Francisco Pérez Arroyo, que desplegaron programas acordes con la representatividad diplomática a la que estaban destinados. Las vicisitudes históricas y los cambios de uso han marcado las transformaciones de estos dos palacios que subsisten en nuestros días como unos grandes desconocidos, a pesar del importantísimo papel que desempeñaron durante muchos años.
\end{abstract}

PALABRAS CLAVE: Arquitectura, Barroco, Marruecos, Tánger, Larache, Siglo XVIII.

\section{Two Late Baroque Palaces in Morocco: The Spain Legations in Larache and Tangier}

\begin{abstract}
An interesting and unknown chapter of the persistence of the baroque style in the Spanish architecture of the XVIII century can be found in Larache and Tangier (Morocco). The king Carlos III ordered the construction of two buildings, which were used like residence of the diplomatic legation to maintain the relationship with the sultan. They still retain a certain mannerist features, although they are situated chronologically in the later baroque. The projects were realized by the architects Juan Fernández and Francisco Pérez Arroyo, who carried out some programmes which took into account the diplomatic representation for which they had been destined. The historical vicissitudes and the changes of theirs use have marked the transformation of these two palaces which survive nowadays although they are completely unknown for us, in spite of the main rol they played for a long time.
\end{abstract}

KEY WORDS: Architecture, Baroque, Larache, Tangier, Morocco, Eighteenth Century.

Recibido: 15 de enero de 2013 / Aceptado: 1 de febrero de 2013.

España y Marruecos han compartido históricamente una frontera que, frente a la idea de impermeabilidad absoluta, ha permitido contactos y transferencias de todo tipo. Tal vez una de las más desconocidas en el campo de la arquitectura haya

\footnotetext{
* BRAVO NIETO, Antonio: «Dos palacios del Barroco tardío en Marruecos: las legaciones diplomáticas de España en Larache y Tánger", Boletín de Arte, n. ${ }^{\circ}$ 34, Departamento de Historia del Arte, Universidad de Málaga, 2013, pp. 33-54, ISSN: 0211-8483.

1 La profesora Dña. Rosario Camacho Martínez viene desarrollando buena parte de su actividad profesional e interés científico sobre el Barroco. En esta contribución que hacemos, en homenaje, para la que es nuestra amiga y maestra, hemos seleccionado un capítulo inédito de la arquitectura del Barroco español desarrollado en Marruecos.
} 
sido la existencia de dos palacios construidos a finales del siglo XVIII y que fueron pensados como sedes diplomáticas de España ante el sultán de Marruecos. Nos referimos en concreto a las legaciones consulares de Larache y de Tánger.

\section{Larache}

Aunque se conocen representaciones diplomáticas anteriores, es a partir del tratado de 1767, en su artículo VII, cuando se establece un consulado general español en Larache ${ }^{2}$ como primera sede diplomática de España en Marruecos. Por indicaciones de Jorge Juan, que en esos momentos encabezaba una embajada al sultán, se nombró a Tomás Bremond para hacerse cargo de la nueva institución del consulado en esta ciudad ${ }^{3}$.

Como consecuencia del establecimiento del cónsul en Larache, fue necesario construir un edificio adecuado a su relevancia, puesto que en esos momentos era la representación diplomática de España en Marruecos, y en 1769 se iniciaron las obras. En el Archivo Histórico Nacional de Madrid (AHN) se conservan varios planos y trazas del proyecto, así como documentación respecto a este edificio. Ninguno de los planos aparece fechado ni firmado, aunque sabemos que el autor fue Juan Fernández «arquitecto de las Reales obras de fortificación de Ceuta». Los datos más importantes sobre este personaje los encontramos en un trabajo de José Luis Gómez Barceló ${ }^{4}$ que nos relata que Fernández fue autor de un proyecto de casas consistoriales para Ceuta (entre 1761 y 1766) y que figura documentalmente como arquitecto y maestro mayor de la Santa Iglesia de Jaén. Este técnico no era por tanto ingeniero militar, aunque desarrollaba su labor en una ciudad donde estos tenían un peso realmente destacado ${ }^{5}$.

Además se conservan tres planos que parecen formar parte de dos momentos distintos de las obras. Los dos primeros hacen referencia a un edificio que se construiría en el futuro, y su factura revela que se hizo por persona que

2 LOURIDO DÍAZ, Ramón, "Le sultan Muhammad B. Abd Allah et l'institution de la représentation consulaire à Tánger", Actas del Congreso Tánger 1880-1956 Contribution à I'histoire récente du Maroc, Rabat, Universidad Mohammed V, 1991, pp. 9-27.

3 RODRÍGUEZ CASADO, Vicente, Política Marroquí de Carlos III, Madrid, CSIC, 1946, p. 125. Archivo Histórico Nacional de Madrid, (AHN), legajo 4.308.

4 GÓMEZ BARCELÓ, José Luis, "Casas consistoriales para Ceuta: realizaciones y proyectos», en Actas del III Congreso Internacional de Hispanistas, Málaga-Ceuta, Algazara-Ciudad de Ceuta, 1998.

5 Este autor no aparece citado por RUIZ OLIVA, José Antonio, Fortificaciones militares de Ceuta: siglos XVI al XVIII, Ceuta, UNED, 2002, ni por CAPEL, Horacio et al., Los ingenieros militares en España siglo XVIII. Repertorio biográfico e inventario de su labor científica y espacial, Barcelona, Serbal, 1983. 
no dominaba completamente la técnica del dibujo. El primer plano ${ }^{6}$ se denomina Esta será la fachada de la casa por el norte, cubierta de Texas la parte que mira al rio solamente. El segundo plano 7 representa una planta, correspondiente a Esta es la perspectiva de la casa, cara al norte, y que mira al rio, por donde entran y salen las embarcaciones en el Puerto. $Y$ finalmente, el tercer plano aparece ejecutado, dentro de una cierta y reveladora sencillez, por persona más ducha en la materia y hace referencia a un edificio ya construido, y por tanto debe ser más fiel al original que los planos anteriores. Se denomina Explicazión del plano de la casa construyda en el Puerto de Larache a expensas de S.M. Catholica para su Consulado General ${ }^{8}$ [1]. En este plano se comprenden una planta del edificio y sus dependencias anejas, con sus dos jardines. La planta dibujada se corresponde con la planta principal, mientras que se señala en la leyenda: "Se advierte que todas las viviendas de arriva tienen sus correspondientes a bajo". También se representa una de las dos fachadas, la principal, remarcada con una bandera de España, y también un perfil que corta el edificio desde su fachada principal hasta el patio trasero.

En cuanto a su cronología, los primeros planos son más cercanos a 1767 y el tercero podría corresponder a un momento entre 1769 y 1773. La existencia de los tres planos nos plantea varios problemas de interpretación, porque son muy diferentes. Los dos primeros representan un edificio de planta cuadrangular de catorce metros de lado que presentaría dos medianeras y dos fachadas, una a norte y la otra a este. La planta dibuja un patio central con galería sobre pilares, lo que permitía que las habitaciones pudieran tener ventanas a la galería interior. Por otra parte se representa la planta baja destinada principalmente a espacios de almacén, junto a un "lugar común" y una caballeriza que tiene su entrada por la fachada al este. Destaca el patio central en cuyo interior habría de situarse una fuente, que recibiría el agua mediante un conducto procedente de la calle ${ }^{9}$.

En este proyecto la fachada principal es la que hacia frente al norte. La fachada al este sin embargo solo tendría dos puertas, distribuidas además de forma irregular, una para acceso a las caballerizas y otra que permitía una entra-

6 AHN, Cartografía, n. ${ }^{\circ}$ 243. Estado, legajo 4.349 121-d. Este plano fue publicado por VILAR, Juan Bautista, Mapas, planos y fortificaciones hispánicos de Marruecos (s. XVI-XX), Madrid, Ministerio de Asuntos Exteriores, 1992, pp. 546 y 550.

7 AHN, Cartografía, n. ${ }^{\circ}$ 241. Estado legajo 4.349 n. ${ }^{\circ}$ 181-b. Este plano fue publicado por VILAR, Juan Bautista, Mapas, planos..., pp. 546 y 551.

8 AHN, Cartografía, n. ${ }^{\circ} 240$. Estado legajo 4.349 n. ${ }^{\circ} 171-a$. Este plano fue publicado en ibid.

9 VILAR, Juan Bautista, Planos, Mapas..., p. 546, hace una errónea interpretación de este sistema de servicio de agua al edificio: "patio central en cuyo centro se sitúa un embarcadero comunicado con el río mediante un canal». 
da lateral al patio galería. El dibujo de la fachada nos confirma que este primer edificio proyectado era más bien un caserón destinado a almacén y sin muchas pretensiones estéticas. La sobria decoración se concentraba en las líneas de imposta y en los enmarques de laterales con sillería, mientras el resto estaba enfoscado. Por su parte los vanos presentaban arcos rebajados con dovelas vistas, bien en sillería bien en ladrillo. La fachada presentaba dos plantas, en la baja se abría una puerta más amplia (aunque solo medía 1,7 metros) y cuatro ventanas (de 0,8 metros de ancho) lo que hubiese dado una imagen de preeminencia de macizo frente al vano y de suma solidez. Finalmente el edificio no tenía cubierta plana, sino techo a dos aguas con teja.

La no correspondencia de este proyecto con lo que finalmente se realiza, determina que debamos hablar de un primer anteproyecto o simple esbozo. Además, la utilidad de este no parece servir de representación consular, sino más bien de almacén de productos en lugar seguro y sólido.

Sin embargo el proyecto definitivo ya muestra grandes diferencias (planta, tamaño, cubierta y estética) y sobre todo un cambio en el programa funcional del propio edificio que pasaba de ser un almacén a un palacio más representativo.

En una carta del embajador Tomás Bremond a Grimaldi, de fecha 15 de enero de $1774^{10}$, se indica que la casa consular de Larache ya estaba totalmente terminada e incluso habían comenzado a detectarse ciertos problemas con la viguería. Bremond informaba que se había venido abajo parte del techo sobre una de las salas, y para evitar mayor ruina se habían puesto varios puntales de acuerdo con el maestro de obras de Larache. Sobre la construcción señala "es cierto que se fabricó con una solidez tan extraordinaria, que siendo el arquitecto de las Reales obras de fortificación de Ceuta D. Juan Fernández el que la principió y la concluyó, más parecía castillo que casa, según la profundidad de los cimientos y grosor de las paredes".

Sin embargo Bremond ya había notado al año algunas grietas, circunstancia que comunicó al comandante de ingenieros de Ceuta, Luis Huet ${ }^{11}$ y al mismo Juan Fernández, aunque ambos dijeron que no existía peligro alguno. De todas formas se mandó a Larache al maestro albañil Pedro Ocaña, que también había trabajado en las obras, que cerró las grietas y se ratificó en la solidez del edificio. Siguiendo la carta del cónsul, también sabemos que en 1773 el edificio sufrió bastante al construirse a su lado unos almacenes cuyas obras de cimientos requirieron varias voladuras y también hubo un importante terremoto en abril, por

10 AHN, Carta de Tomás Bremond a Grimaldi, 15 de enero de 1774. Estado, Leg. 4349, 6 fol.

11 Luis Huet, ingeniero militar que despliega una intensa obra en Ceuta y posteriormente en Cuba. 
12 artículos $\quad$ Dos palacios del Barroco tardío...

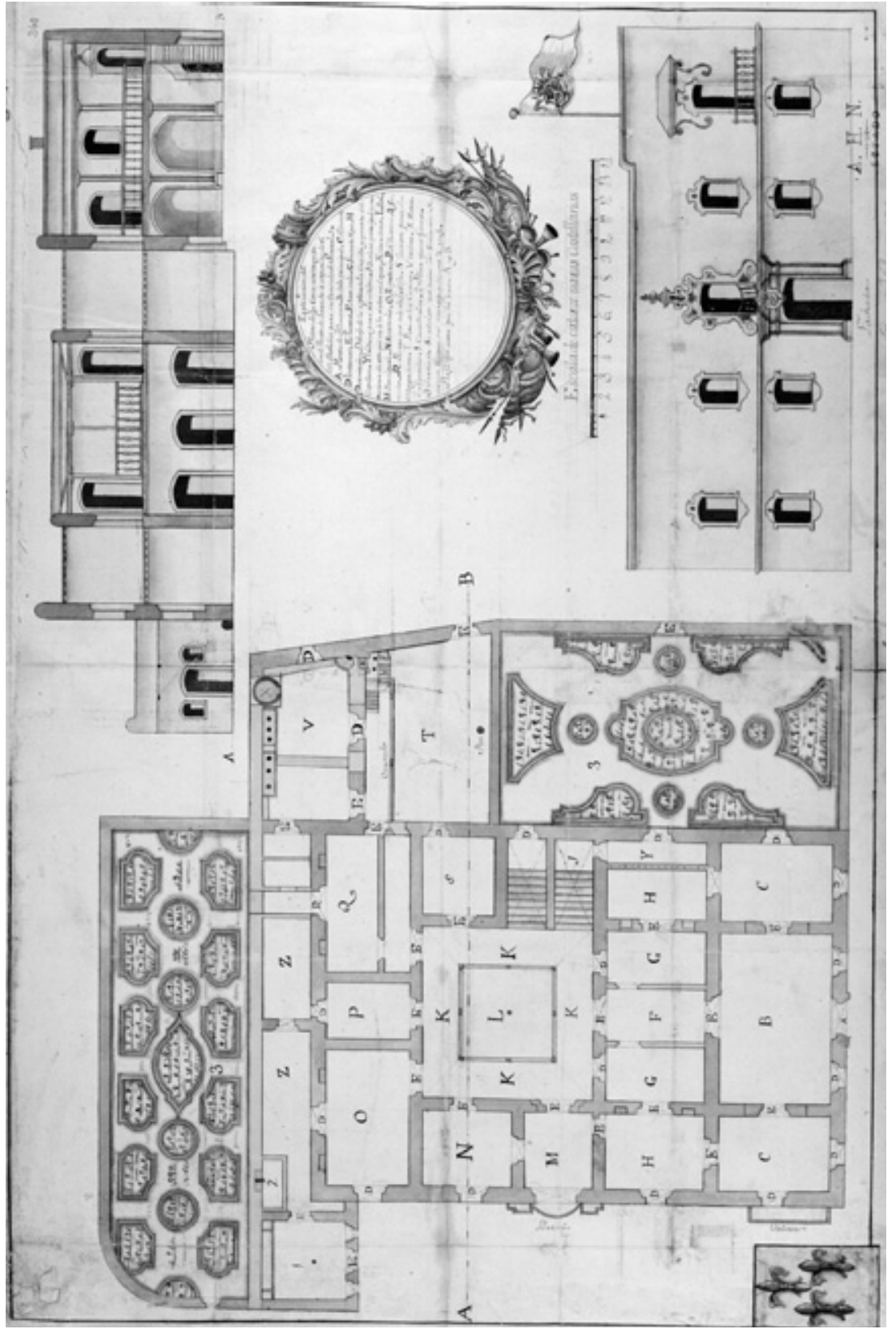

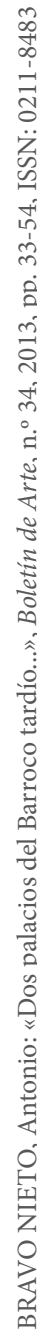

Catholica para su Consulado General. AHN, Cartografía, n. ${ }^{\circ} 240$. Estado legajo 4349 n. ${ }^{\circ} 171$-a 
lo que en el verano del mismo año Bremond hizo venir a Larache, desde la ciudad de Salé, al maestro albañil Joseph Marchito. Este dijo, en contradicción con los informes anteriores, que la obra tenía malos cimientos por lo que el cónsul, alarmado, solicitaba que debería mandarse desde España un perito para estudiar si se podía arreglar o bien se mandaba derribar.

Nuestra opinión es que el tercer plano ${ }^{12}$ muestra la obra un poco después de haber sido escrita esta carta, y que la opción que finalmente se tomó sería la de reparar los problemas habidos, puesto que el edificio perduró posteriormente.

El plano nos muestra una planta que tiende al rectángulo con una fachada principal al este que tiene 22,5 metros por una fachada secundaria al norte que mide 15 metros. Sin embargo, si sumamos los jardines que lindan con el oeste y con el sur, las dimensiones reales del palacio son 25 por 31 metros de planta.

El núcleo principal de habitaciones se establece en sus dos plantas en torno a un patio central cuadrangular, que presenta una galería perimetral cubierta y con pretil de balaustrada. Esta galería se apoya sobre lo que pudieran ser cuatro pilares o columnas con basa y capitel, siendo una tipología muy común en la arquitectura española desde el siglo XVI hasta el XIX.

La planta nos sitúa ante un edificio destinado a funciones de palacio y representativas: las habitaciones principales destinadas a salón, alcobas, secretaría y dormitorios dan a fachada y en lugar más discreto se sitúan las típicas habitaciones del servicio con cuarto para el mayordomo, repostería, alhacena y comedor. Los dos dormitorios disponían de una habitación previa que servía como guardarropa, precedidas de una antesala. Las habitaciones estaban casi todas unidas entre sí por puertas que las atravesaban en eje, salvo las del servicio que carecían de ellas.

Las habitaciones del servicio daban a un callejón lateral destinado a corrales, y la del mayordomo a un patio posterior donde se situaba la cocina (que contaba con horno) evitando los humos y olores en el interior del núcleo principal de la vivienda. La comida ya cocinada pasaba por un corredor a la zona de comedor, comunicando así dos núcleos diferentes en el mismo edificio.

El palacio contaba con una capilla y casa del capellán en un momento en el que la propia representación de la Iglesia católica debía ser asumida por el Esta-

12 AHN, Cartografía, n. ${ }^{\circ}$ 240. Estado, legajo 4349, n. ${ }^{\circ} 171-a$. Este plano fue publicado por VILAR, Juan Bautista, Planos, Mapas..., pp. 545-546 y 549, en blanco y negro. También por BRAVO NIETO, Antonio, Arquitectura y urbanismo español en el norte de Marruecos, Sevilla, Junta de Andalucía, 2000, p. 86, donde agradecíamos especialmente al historiador $\mathrm{D}$. Ramón Lourido la información documental de los proyectos. También es recogido, sin citar la procedencia, por DUCLOS BAUTISTA, Guillermo y CAMPOS JARA, Pedro, Larache, Evolución urbana, Sevilla, Junta de Andalucía, 2001, p. 42. 
do español e integrada en el propio núcleo del edificio. Como elemento realmente significativo del ambiente barroco en el que se sitúa el programa edificatorio, diremos que contaba con una tribuna situada en la planta principal desde donde se podía oír misa en la capilla situada en la planta baja.

Aunque no figura en el plano, la planta baja serviría para ubicar almacenes y cuartos. El acceso de una planta a otra se realizaba por una escalera amplia situada en uno de los vértices del patio, como era habitual en este tipo de construcciones, cuya prolongación conduciría a la azotea que era de cubierta plana, a diferencia del primer edificio proyectado.

Por su parte, las caballerizas no están en el propio núcleo de la casa, sino en una habitación independiente con salida directa a la calle y conectada con los corrales, donde se situaba una fuente con pileta para bebida de los caballos y monturas.

Los jardines son un importante e interesante elemento dentro del programa, con parterres que presentan cuidadas figuras geométricas que transforman este espacio en un verdadero teatro del poder y espejo de representatividad del cónsul español en Marruecos.

Por su parte la fachada ${ }^{13}$ nos muestra un edificio característico de la tradición barroca. Su composición se ordena en dos plantas, con un fuerte horizontalismo determinado por cornisas e impostas, aunque el eje principal se remarca con portada noble, balcón curvo en la planta principal y enmarques de todos los vanos con molduras barroquizantes. Como elementos interesantes del propio plano señalaremos la cartela que alberga la leyenda, que es característica en sus elementos ornamentales del estilo rococó y la bandera de Carlos III dibujada sobre fondo blanco ${ }^{14}$.

La parquedad de información sobre este edificio en fechas posteriores es exasperante. Se desconocen descripciones o referencias escritas, y como tal edificio cae totalmente en el olvido, haciendo pensar a algunos autores que pudiera haberse demolido ${ }^{15}$.

13 VILAR, Juan Bautista, Planos, Mapas..., p. 545 señala «la fachada [...] es una acertada combinación del churrigueresco madrileño con elementos de la arquitectura canaria y colonial». Al respecto, el profesor Sergio Ramírez de la Universidad de Málaga nos ha situado de forma clara y rotunda la filiación de esta obra en un contexto totalmente andaluz, relacionando su estética con la fachada de la iglesia parroquial de los Remedios de Estepona.

14 La bandera muestra el escudo de España sobre fondo blanco y rodeado por el Toisón de Oro. Representa la bandera que Carlos III implantó en 1760 al suprimir el collar del Espíritu Santo. La bandera roja y amarilla que rige en la actualidad se debe a un R.D. de 28 de mayo de 1785.

15 No existe ninguna referencia conocida en la extensa y minuciosa bibliografía de GIL GRIMAU, Rodolfo, Aproximación a una bibliografía española sobre el norte de África. I: 1850-1980, Madrid, Ministerio de Asuntos Exteriores, 1981. DUCLOS BAUTISTA, Guillermo y CAMPOS JARA, Pedro, Larache, Evolución urbana..., p. 42. Es sorprendente que este documentado trabajo sobre Larache no repare en el que es sin duda uno de los principales edificios de esta ciudad, y el de tradición española más rele- 
Sin embargo, revisando fondos de imágenes antiguas de la ciudad de Larache, pudimos encontrar una fotografía sorprendente, recogida por Fernando Valderrama ${ }^{16}$ [2], donde aparece un edificio, el colegio Muley Abdeselam Mechich (Mulay Abd al-Salam B. Masis), cuya imagen sin lugar a dudas pertenece a una construcción de finales del siglo XVIII y de extraordinario parecido al proyecto que hemos comentado. A pesar de esto, Valderrama nos relata en su obra que ese edificio fue construido e inaugurado el 12 de enero de $1950^{17}$. Sin poner en duda la afirmación de una persona del prestigio de Valderrama, estamos totalmente seguros que estas obras que cita no fueron de nueva construcción, sino de adaptación del edificio anterior a un nuevo uso escolar. La fotografía no deja lugar a dudas, puesto que es evidente que el edificio no había sido demolido totalmente y persistía en esa fecha con transformaciones. Destacaba todavía, a mediados de los años cincuenta del pasado siglo XX, el cornisamento potente, el eje central que se potencia con un resalte de fachada y la ordenación de las ventanas en grupos de dos, a los laterales. El balcón curvo y su forja con forma barroca, la puerta, así como las molduras rococó que enmarcaban los vanos del eje central, nos indican que se trata del mismo edificio que por entonces había sido readaptado y modificado pero no demolido.

Ante el estado de ausencia documental hemos realizado una reinterpretación sobre los volúmenes que figuran en el proyecto original y los que actualmente persisten. Utilizando un sector del plano catastral de Larache donde está el actual colegio, hemos superpuesto la planta del proyecto original y con ello llegado a las siguientes conclusiones: la fachada es exactamente igual (lo que ya sabíamos por las fotografías de 1950) y tiene las mismas medidas y proporciones que la proyectada: unos 22,5 metros. El jardín situado a la izquierda de la fachada (que daba cara a la calle Real) y la zona de corrales, han sido edificados y en su lugar se encuentra un edificio que asume parcialmente su planta. Respecto al edificio noble, parece haberse mantenido la fachada, la primera crujía y la galería del patio que da frente a estas habitaciones. Ha desaparecido el patio cuadrangular centrado, y la zona de escalera, mientras que con mucha probabilidad se haya reaprovechado parte de la estructura del palacio que da frente al

vante. La única referencia que se hace al edificio del antiguo consulado presupone que fue demolido: "ocupando seguramente el solar donde hoy se asienta el colegio Mulay Abd al-Salam B. Masis". 16 VALDERRAMA MARTíNEZ, Fernando, Historia de la Acción Cultural de España en Marruecos (19121956), Tetuán, Editora Marroquí, 1956, pp. 176-177.

17 Señala Fernando Valderrama (Historia de la Acción...) que el 14 de febrero de 1953 se le puso al colegio el nombre de Muley Abdeselam Mechich, Ilamándose antes Escuela Primaria Musulmana de niños n. ${ }^{\circ}$ 1. Dispone de siete aulas, sala de profesores, biblioteca, salón de actos, comedor, cocina y patios para el recreo. 


E artículos $\quad$ Dos palacios del Barroco tardío...

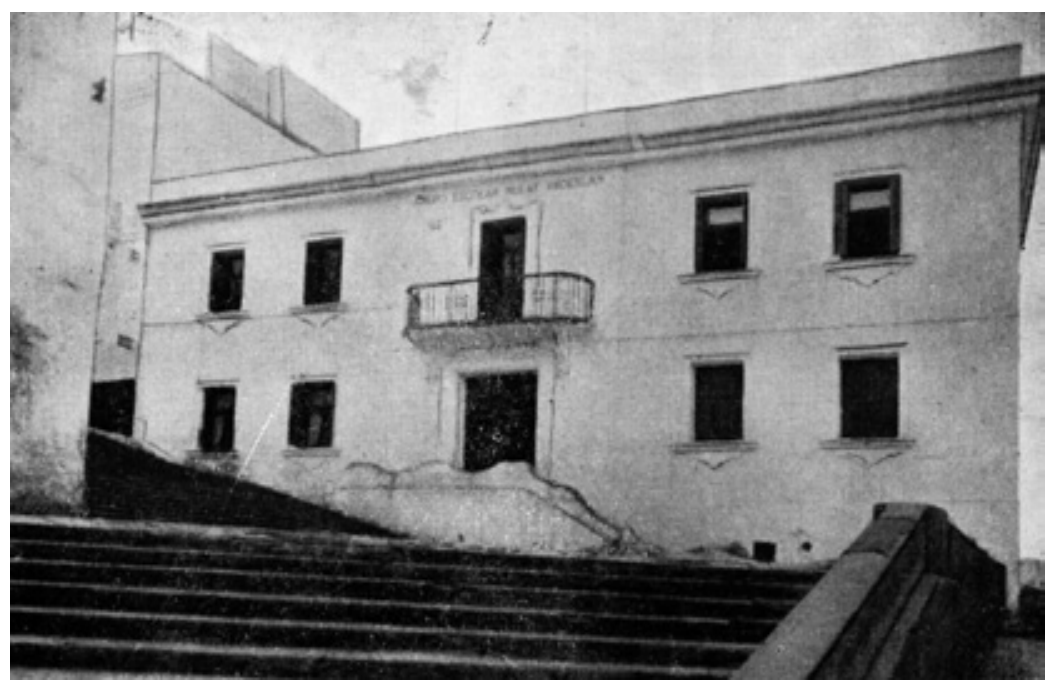


norte, actual calle Z. Nassiria. En resumen, la nueva obra de 1950 reaprovechó muros y estructuras anteriores, dotando al espacio de mayor funcionalidad y prolongando con una nave nueva la fachada norte, que actualmente es casi el doble de tamaño que la original ${ }^{18}$.

Actualmente se mantiene la fachada con la misma disposición [3], aunque las molduras barrocas han sido picadas y presenta una superficie lisa, pero conserva el resalte del eje central, el cornisamento y la misma disposición de los vanos.

Es interesante destacar la importancia de este edificio y su historia, vinculada al primer establecimiento diplomático de España en Marruecos, construcción que por otra parte ha pasado totalmente desapercibida hasta este momento para la historiografía.

\section{Tánger}

La historia del edificio de la legación española en la ciudad de Tánger presenta un gran paralelismo histórico con la de Larache, pero al mismo tiempo manifiesta una personalidad muy acusada, a lo que se suma que se conserva actualmente casi en su totalidad.

Aunque el cónsul español en Marruecos se había ubicado en Larache durante algunos años, posteriormente el sultán Muley Mohammed ben Abdallah decide concentrar a todos los cónsules extranjeros en la ciudad de Tánger, lo que ya empieza a vislumbrase en $1777^{19}$. Este deseo del sultán transforma a esta ciudad en la capital diplomática del país ${ }^{20}$.

Aunque la representación española en Tánger se inicia en 1780 cuando el padre Boltas desempeña de facto el papel de cónsul, será en 1784 cuando de forma definitiva se nombra a Juan Manuel Salmón como cónsul general de España ante Marruecos. La necesidad de alojamiento, la funcionalidad exigida y la importancia de la ciudad que iba a ser la capital donde se concentraran todas las embajadas extranjeras, determina la necesidad de un nuevo edificio representativo [4].

En el AHN se conservan dos planos diferentes del edificio, el primero es Planos y perfil de una casa que esta en la plaza de Tanxer: esqueletada asta reci-

18 Agradecemos a D. Miguel Ruiz Rueda las gestiones realizadas en Larache.

19 GONZÁLEZ HIDALGO, José Luis, Tánger y la diplomacia española, Madrid, Asociación Española de Africanistas, 1997.

20 LOURIDO DÍAS, Ramón, Marruecos y el mundo exterior en la segunda mitad del siglo XVIII, Madrid, Agencia Española de Cooperación Internacional, 1989, p. 587. 


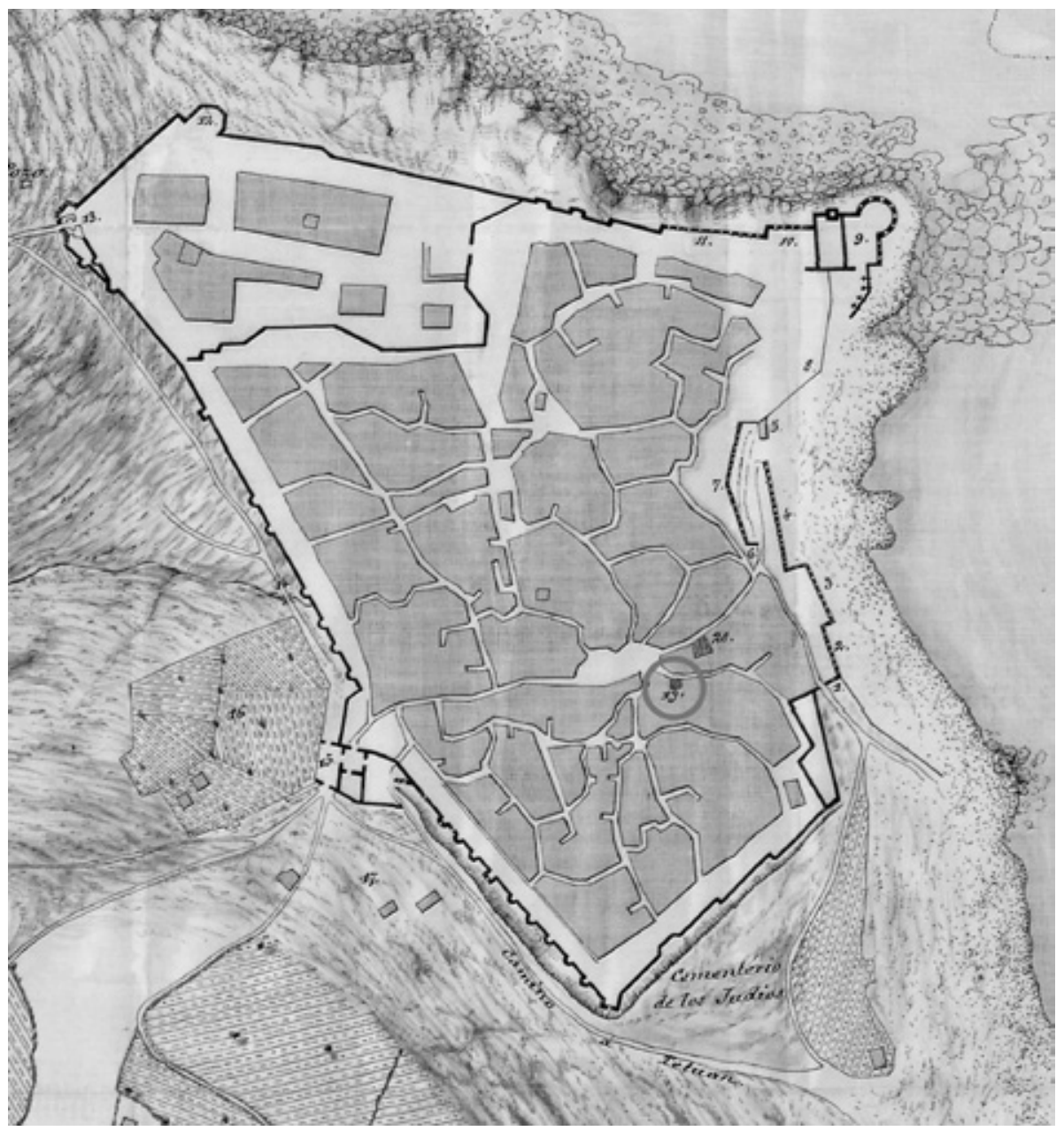

4. Plano de Tánger, 1882. Se aprecia la ubicación de la legación en el centro de la medina (n. $\left.{ }^{\circ} 19\right)$

bos de maderas en paredes maestras ${ }^{21}$. Se trata de un plano de la obra a medio realizar, por lo que su datación podría llevarnos a 1785. Su autor, como sabemos por otros documentos, es Francisco Pérrez de Arroyo. Los preparativos de compra los realiza Salmón a lo largo de 1784 y las obras debieron empezar pronto porque en 1785 ya estaba en construcción.

21 VILAR, Juan Bautista, Planos, Mapas..., p. 395. AHN, Cartografía 298 a y b. No se referencia que se trata de dos planos de épocas distintas. 
Por lo que respecta al proyecto señalaremos que en todos estos edificios uno de los problemas más importantes era la ubicación de los servicios, tanto los de cocina como las caballerizas. En Larache ya veíamos el mismo problema en el proyecto de la legación, que allí fue resuelto ubicando esos servicios en dependencias fuera del cuerpo principal del edificio. En Tánger la situación era la misma, aunque gracias a este primer plano vemos que para ubicarlos se utilizaba un estrecho solar que existía a la izquierda de la construcción principal ${ }^{22}$. Este solar albergaría estancias destinadas a horno, carbonera, "oficina común», corral y caballeriza con salida directa a la calle. Sin embargo otras estancias como cocina, repostería, despensa y bodega, así como dos cuadras se situarían en la propia fachada principal del edificio, porque no cabían en sus reducidas dimensiones.

Debió ser en estos momentos cuando el cónsul amplió el solar de la legación comprando una casa y patio en su parte posterior, lo que permitió al arquitecto contar con más espacio en la zona trasera. Esta ampliación del solar, no alteró en suma la planta principal del edificio, pero sí la disposición de algunas de sus funciones, porque todos los servicios se dispondrían en el solar trasero.

En este primer proyecto, la fachada se dibuja de forma muy sobria, con portada de sillería de corte clásico, marcadas líneas de imposta y cornisa. El eje principal de portada se potenciaba con sillería y con una molduración barroca en el vano, y a ambos lados del eje de portada dos pares de ventanas, tanto en el bajo como en el principal.

La legación fue inaugurada finalmente en $1786^{23}$. Una carta del cónsul Salmón a Floridablanca de fecha 25 de abril de $1787^{24}$ daba cuenta de todos los gastos habidos desde que se compró el solar hasta ese momento, cuando ya se había producido su entera conclusión: 288.122 reales y 6 maravedises de vellón.

En las obras trabajaron operarios españoles (casi todos de Ceuta) y marroquíes, y parte de los materiales de construcción vinieron de España (concretamente de Tarifa y con un valor de 6.000 duros). El cónsul Salmón, en esta misma carta, describe el edificio:

La casa se ha hecho con la solidez que corresponde: no tiene en sí ningún adorno ostentoso, ny inútil, pero esta de mucho gusto, bien distribuida y comoda para el fin que se ha hecho. A costado sin comparación mucho más de lo que calculó

22 Este solar durante el transcurso de las obras fue edificado como hospicio de la misión con capilla. 23 VILAR, Juan Bautista, Planos, Mapas..., p. 395, confunde la cronología y adjudica este edificio a los últimos años del reinado de Fernando VII, AHN legajo 5823 (2).

24 AHN Estado, Legajo 4346 (2), 10 folios. Por su parte las cuentas las debía revisar el Tribunal de la Contaduría Mayor. 
el alarife de Tarifa Don Francisco Pérez por cuia dirección a corrido toda [...] es poco a proporción del concepto que con esta obra se ha adquirido la nación entre estas gentes, y aun de los mismos europeos, porque la casa esta respirando magestad y diciendo quien es su amo, tanto que a varios principales moros de esta corte que han estado a verla, les he oído y me lo han dicho personalmente, es questa obra es una prueba real de la verdadera amistad que el rey nuestro señor tiene a este soberano marroquí y de sus pacificas intenciones para con esta potencia.

Es muy interesante la reflexión que se realiza por parte de Salmón sobre la distribución real del presupuesto, porque 116.836 reales y 10 maravedises (incluidos los 3.000 duros de la compra del terreno) se había empleado para pagar a propietarios y obreros marroquíes, mientras que solo 7.000 duros se habían invertido en efectos venidos de España y en pagos a obreros españoles. Por tanto la inversión había revertido en gran parte sobre la propia población marroquí de Tánger ${ }^{25}$.

En el momento de enviar la citada carta, el cónsul Salmón no contaba aún en su poder con un plano general que le había solicitado al maestro principal de las obras, Francisco Pérez de Arroyo, que estaba entonces construyendo el nuevo Hospicio de la Misión, contiguo a la casa consular y cuya salud no era buena.

$Y$ este es el origen del segundo plano que conocemos: Plano, alzada y perfiles de los dos cuerpos que forman la casa que de orden y quenta de S.M.C. se a edificado en la plaza de Tanger para avitacion del Consul General de España en los dominios de Marruecos [5]. Se trata de un documento de gran interés que refleja el edificio tal y como estaba ya construido. Existe un problema de fechas sobre este plano. Juan Bautista Vilar lo sitúa entre 1832 y 1835. Sin embargo sabemos por la carta de Salmón de 25 de abril de 1787 que el propio arquitecto de la obra, Arroyo, estaba terminando de dibujarlo y es él también quien lo firma, por lo que la datación nos llevaría hacia el mismo año 1787 o muy poco tiempo después.

Por lo que respecta al edificio, diremos que el solar que ocupa es privilegiado, formando un cuadrado que presenta dos fachadas a la calle (norte y oeste). Al este tenía contiguo un pequeño y estrecho solar convertido durante el transcurso de las obras en Hospicio de la Misión, y a continuación de la misma calle se encontraba la legación de Portugal. Al fondo del solar, lo que sería medianera sur, existía un amplio espacio irregular en el que se situaban servicios como carbonera, gallinero, corral y caballerizas, agrupados alrededor de un patio y que tenía una puerta falsa de salida a una calle posterior, para no tener que pasar

25 ESTEBÁNEZ CALDERÓN, Serafín, Manual del Oficial en Marruecos, Madrid, Ignacio Boix, 1844, p. 89: "palacio muy capaz y hermoso», señalaba que había costado 16.000 duros. 


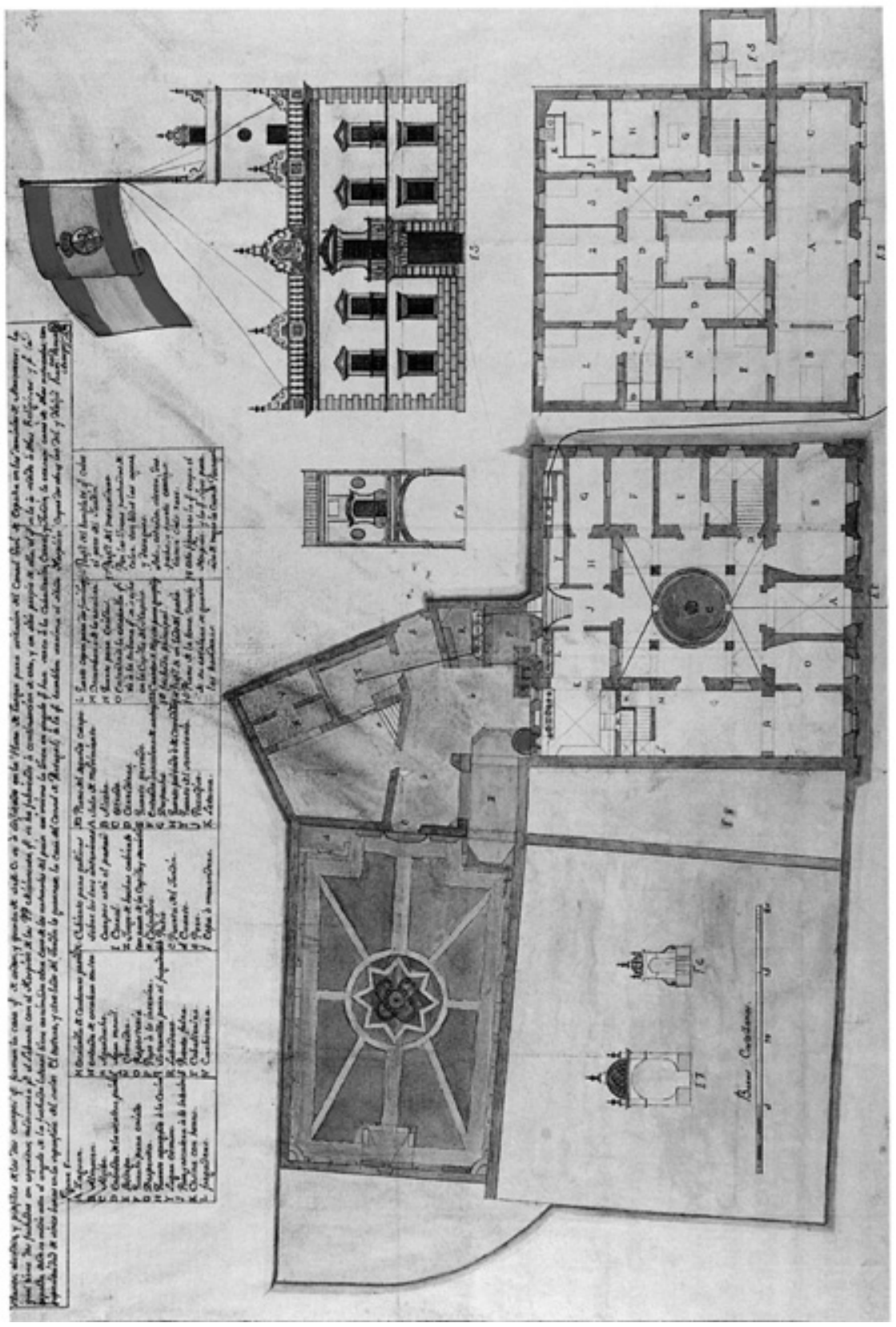

5. Plano, alzada y perfiles de los dos cuerpos que forman la casa que de orden y quenta de S.M.C. se a edificado en la plaza de Tanger para avitacion del Consul General de España en los dominios de Marruecos. AHN, Cartografía 298 
por el núcleo principal del palacio. También se accedía por ese patio a un solar rectangular donde se situaba un amplio jardín con merendero, inserto en el corazón de la manzana. Destaca de este espacio el carácter de jardín privado, con parterres que formaban figuras geométricas en forma de estrella entre las que destacaba una estrella de ocho puntas formada por dos cuadrados girados, y un templete en su centro como lugar privado y de recreo del cónsul.

El edificio principal presenta patio central que forma una galería semicubierta, apoyada sobre cuatro columnas y en el centro se sitúa un aljibe con fuente artística. En la planta baja y a continuación de la portada se ubica el zaguán, que permite acceso directo al patio. Desde este patio se va dando entrada a las habitaciones, que son en esta planta todas destinadas a servicio: repostería, almacén, despensa y cuarto de los criados en una zona, cocina al fondo, y un amplísimo comedor en otra de las zonas. En eje con la puerta principal pero situado al fondo del solar, se sitúa la puerta de acceso al patio posterior. Y en un vértice del mismo patio central arranca la escalera para acceder a la planta principal.

Esta planta presenta el mismo diseño que el bajo, nucleadas todas las habitaciones en torno a la galería cubierta que rodea el patio. A la fachada principal se sitúan las habitaciones más representativas: sala de recibimiento, estrado y alcoba con cuarto privado, y a la otra fachada el despacho, sala de comedidos o privado y cuarto del secretario. Al fondo se situaban los cuartos para huéspedes.

Finalmente unas escaleras permiten subir a la azotea con la torre ubicada en un lateral de la fachada al este, lugar preeminente donde se guardaban las banderas reglamentarias de una sede diplomática y que permitía, gracias a sus dos alturas, una vista tan privilegiada como estratégica.

Destacaremos dos elementos interesantes del proyecto. El primero es un claro ejemplo del carácter barroco del edificio y se trata de un artificio por el que a través de unas escaleras de la planta principal se podía acceder a una tribuna que daba sobre la capilla del hospicio contiguo, como mecanismo para poder asistir a oficios religiosos desde el propio palacio y en sitio privilegiado, sin necesidad de tener que salir de la legación. El segundo elemento es la ubicación de un espacio rectangular cubierto para el juego de pelotas de bochas. Este juego, parecido a la petanca, es de origen americano y se puso de moda en España a partir de 1783, por lo que su existencia en la legación demuestra el grado de aceptación que había adquirido entre la población española y, en este caso, también la tangerina.

En cuanto a los aspectos más ligados a la estética, señalaremos el tono barroquizante del conjunto, que sigue imperando a pesar de la fecha ya tardía de su construcción. No vemos en su programa formal los parámetros que nos 
pudieran permitir integrar este edificio entre las construcciones neoclásicas porque perduran los programas imperantes en el mundo barroco y se remontan en su portada incluso a un claro manierismo. La fachada principal es representada con un fuerte carácter palaciego, en sus dos plantas que aparecen enmarcadas por franjas de sillería en los laterales, mientras que horizontalmente destaca el zócalo, la línea de imposta y la cornisa. El conjunto se remata con balaustrada y remates barroquizantes formados por curvas y quiebros que pudieron contener algún elemento heráldico.

El marcado horizontalismo de la fachada se equilibra con el eje vertical formado por la portada principal de piedra de sillería y tipología manierista, y encima se situaba una ventana con balcón con forja y remates barrocos. El sentido axial domina la composición, quedando distribuidos los vanos de forma simétrica: dos a cada lado. Los vanos de la planta baja presentaban guardapolvos rectos mientras que en la principal aparecen rematados con frontones triangulares, dos y dos.

La torre también tenía esos remates barroquizantes, al igual que los templetes que cubrían el pozo del jardín y el del merendero, que reflejan un fuerte carácter andaluz en sus formas blancas y de cerámica polícroma.

El edificio quedó totalmente terminado en 1787, aunque también se han documentado obras entre 1832 y 1835 que recoge Juan Bautista Vilar ${ }^{26}$. Posteriormente la ausencia de datos y referencias es el denominador común de este palacio, que se convierte en uno de los edificios más importantes de la medina tangerina durante el siglo XIX y primeros años del XX, pero que también pasa a un segundo plano cuando la ciudad moderna de Tánger comienza a construirse fuera de las murallas ${ }^{27}$ [6]. Es entonces cuando el edificio deja de tener sentido y cuando las legaciones de los países comienzan a construirse en la ciudad nueva, lejos de las estrechas y concurridas calles de la medina. El antiguo palacio queda descentrado y un tanto fuera de lugar con respecto a una ciudad moderna que ensanchaba sus límites olvidando su zona antigua, y la legación era una de ellas. El traslado definitivo a la nueva sede consular se produce en 1918, durante el mandato del cónsul Francisco Serrat, y el antiguo edificio comenzó a ser remodelado el 18 de agosto de 1924 para adaptarlo al Correo Español que permanece en ese lugar hasta $1958^{28}$. Posteriormente, diferentes avatares dieron lugar a un desenlace tan inesperado como sorprendente, que no ha dejado de ser criticado

26 VILAR, Juan Bautista, Planos, Mapas..., p. 395. Documenta reparaciones en la casa consular de Tánger, a petición del cónsul, 1832-1835 AHN legajo 5283 (2).

27 BRAVO NIETO, Antonio, Arquitectura y urbanismo..., pp. 121-127.

28 COLÓN, Antonio, "Adiós al Correo Español de Tánger», ABC, 7 de marzo de 1958, p. 18. 
6. Vista del edificio de la legación (junto al primitivo

Correo Español) en una

imagen de 1911. Blanco y

Negro, n. ${ }^{\circ} 1042$

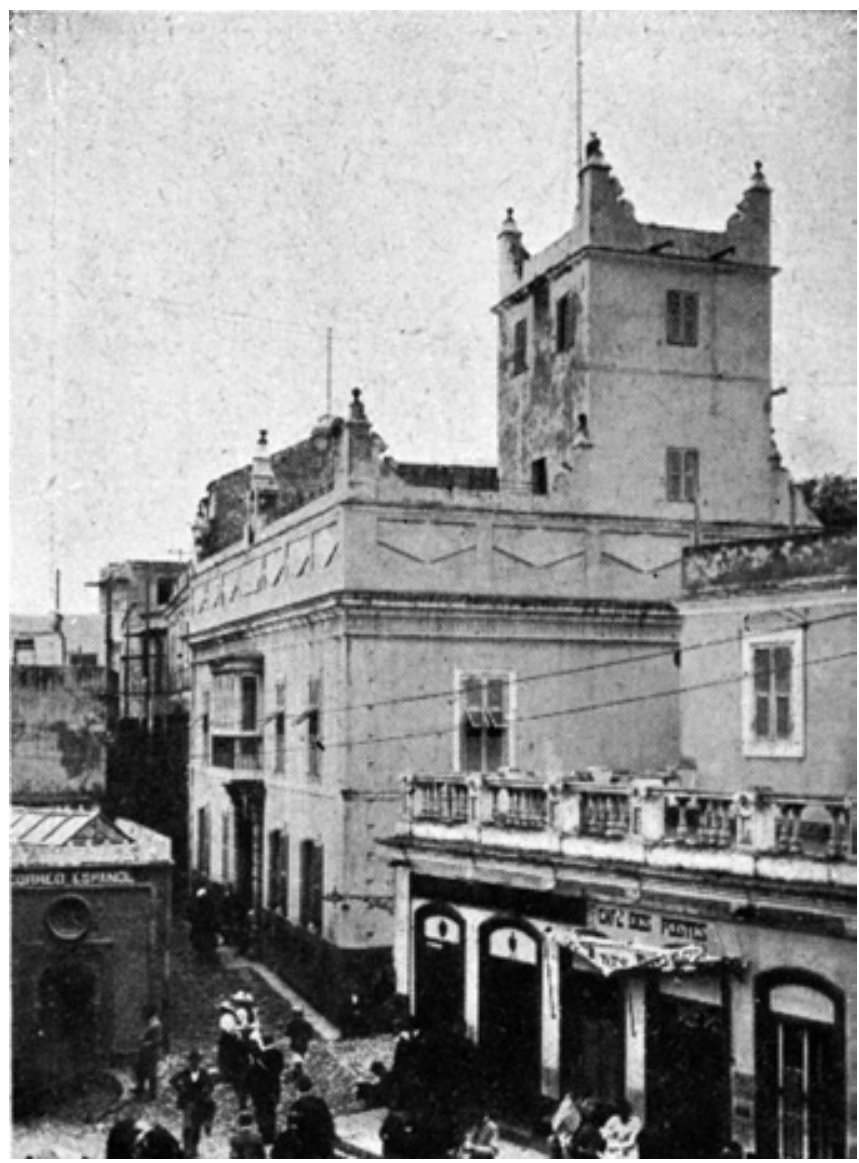

en todos los círculos culturales tangerinos desde que ocurrió, porque el edificio fue vendido por el Estado español y convertido en una pensión de gama modesta, situación en la que se encuentra en la actualidad.

El edificio hasta este momento no ha sido objeto de los estudios que su importancia hubiera aconsejado, y no existe ninguna monografía al respecto, salvo un pequeño y precursor informe realizado en 1991 por Nadia Erzini ${ }^{29}$. En él la profesora Erzini daba su opinión, señalando que se trataba sin duda del principal edificio español de Tánger, cuya memoria debía ser recuperada [7].

29 ERZINI, Nadia, "Informe sobre el antiguo consulado español en la medina de Tánger», informe mecanografiado inédito, 12 de noviembre de 1991, 2 folios. Lo firma como profesora de la Universidad de Oxford. 


\section{OE artículos}

Antonio Bravo Nieto

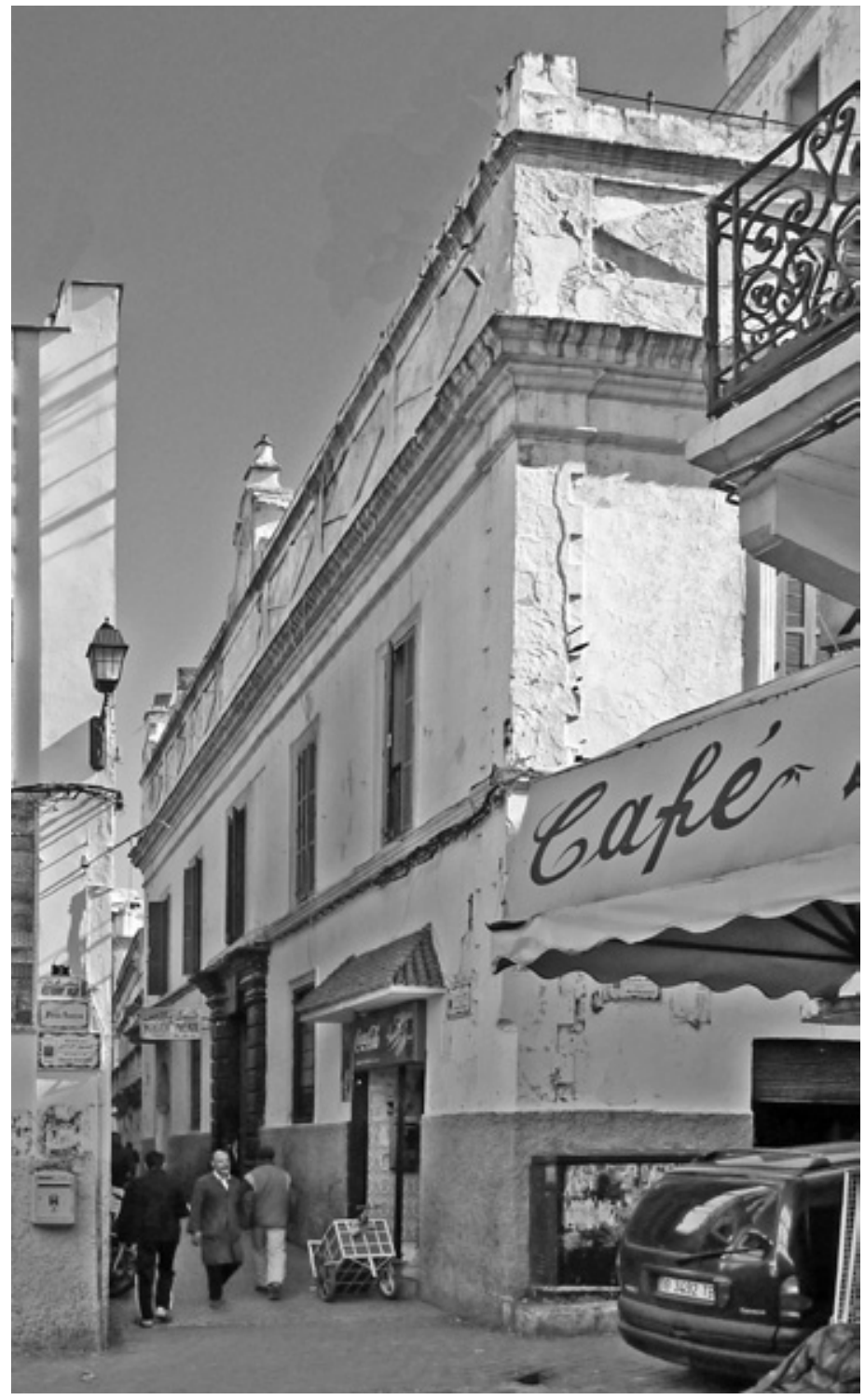

7. Vista actual del edificio, transformado en Pensión Palace

El edificio se encuentra en una zona importante de la medina, concretamente en un lateral del Ilamado Zoco Chico (calle Mohktar Ahardam n. ${ }^{\circ}$ 2, antigua calle del Correo Español o del Correo), en el camino que bajaba hacia el puerto. Por tanto lugar privilegiado en el corazón de la medina, en la zona más 


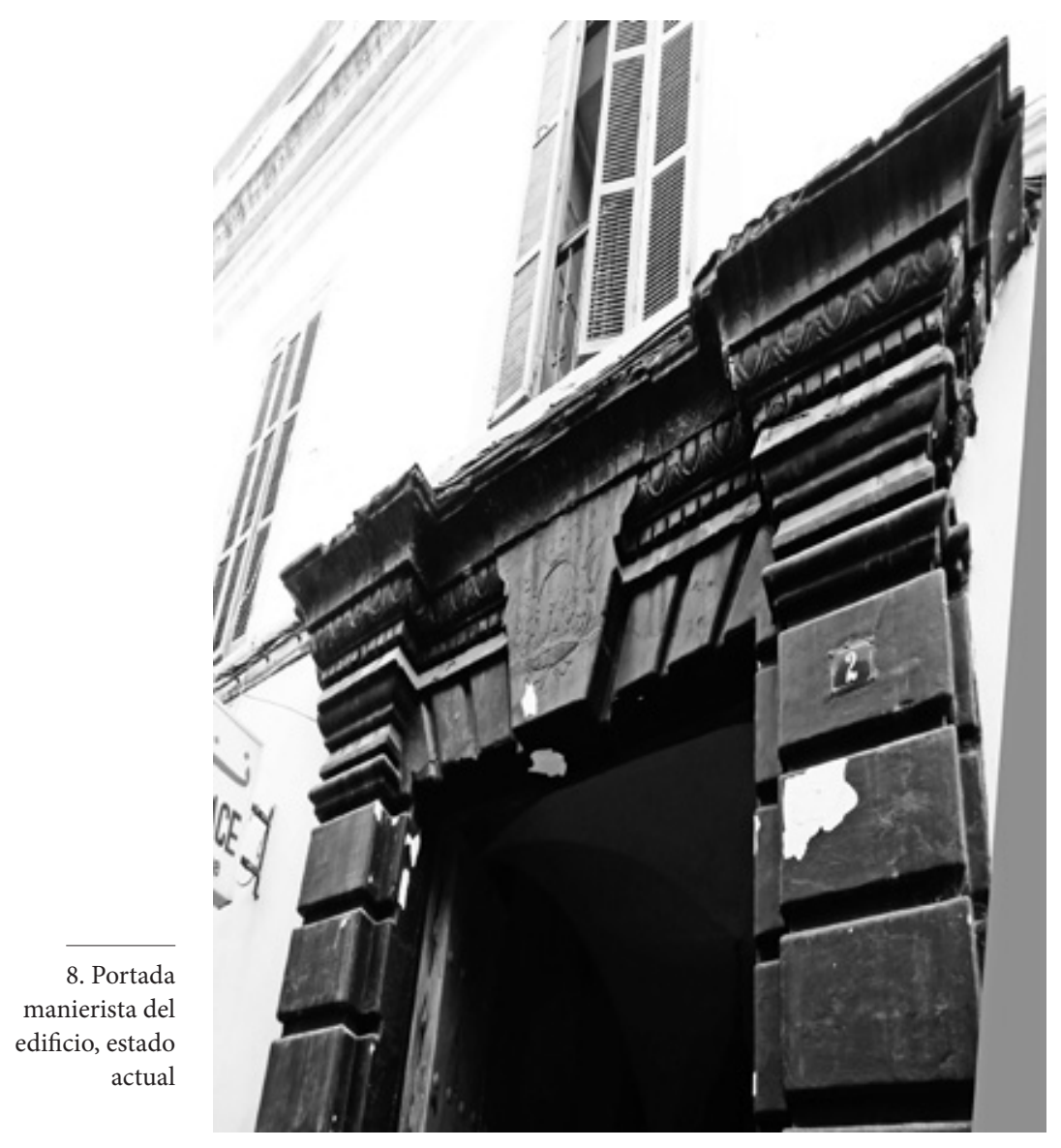

vital de la ciudad antigua ${ }^{30}$. Actualmente aparece muy constreñido en una calle estrecha, pero esa no era su imagen durante los siglos XVIII o XIX, ni siquiera en los primeros años del XX, porque entonces estaba rodeado de casitas bajas, entre las que sobresalía el volumen macizo de la legación.

La imagen que presentaba a principios del siglo XX no difería del dibujo de fachada que hemos descrito en el proyecto, salvo que el balcón central se había convertido en una especie de mirador cerrado muy característico del XIX. La portada de sillería tiene un diseño muy manierista [8]: dos jambas con sendas pilastras almohadilladas y el dintel que presenta dovelas y sobre estos un cor-

30 Queremos agradecer la colaboración de los señores Rachid Tafersitti, Rachid Belhadj, Mustapha Ghottes, Álvaro Montero López y Jamal Bennis en la obtención de imágenes del edificio. 
nisamento quebrado que se apoya sobre relieve de ovas. En su centro, la clave encierra un espacio liso en el que se incluye una referencia al rey de España: las iniciales C.R. "por Carlos III".

Se aprecian algunas diferencias con respecto al proyecto original en la fachada principal: los guardapolvos y frontones del proyecto se habían simplificado en leves recercados de vanos, y la balaustrada original se ha convertido en un pretil con murete cuartelado con figuras geométricas. En cuanto a los vanos, dos de las ventanas de la planta baja han sido convertidas en puertas: una de ellas albergó uno de los buzones de correos que se instaló en el edificio (bajo un arco de estética arabizante) y la otra muestra un establecimiento comercial con acceso independiente a fachada. El balcón central del principal ha desaparecido y se queda actualmente en simple ventana.

La fachada lateral sí presenta más alteraciones en la disposición de los vanos, y se muestra hoy día más irregular, aunque mantiene la simetría horizontal que determinan zócalos, línea de imposta y cornisa, sobresaliendo el cuerpo de la torre que está adosado a esta fachada. Algunos de los vanos en esta zona han sido cegados.

El interior que podemos observar hoy día se corresponde por regla general con lo proyectado en 1786, con las lógicas transformaciones sufridas en los repetidos cambios de uso del edificio.

La portada nos da entrada al zaguán, donde actualmente se encuentra la recepción de la pensión. Destacan los azulejos de filiación arabizante del siglo XX con motivos estrellados y fuerte colorido, el suelo con baldosa hidráulica de los primeros decenios del mismo siglo, así como la puerta que nos da acceso al patio, enmarcada por barroco enmarque. La cubierta del zaguán es una bóveda de arista

El patio tiene losas de mármol blanco y negro. En su centro ajardinado existió una tribuna con cúpula que se alzaba sobre el pozo de la cisterna, pero actualmente en este espacio se sitúa una fuente de tres tazas superpuestas que se asienta sobre cuatro leones.

El patio con galería se estructura en cuatro columnas que voltean a su vez cuatro arcos cada una, dos de ellos son de medio punto y descansan sobre las paredes (formando entre ellos sendas bóvedas vaídas), mientras que los otros dos son rebajados y descansan sobre las columnas colindantes [9]. Las columnas son de orden toscano sobre las que se eleva un cuerpo cuadrangular a modo de cimacio que presenta letras en árabe ${ }^{31}$, y actualmente están jaspeadas con

31 البل إلاغالبل. La Ghaliba illa Allah, cuya traducción es «No hay vencedor sino Dios». 


e artículos $\quad$ Dos palacios del Barroco tardío...

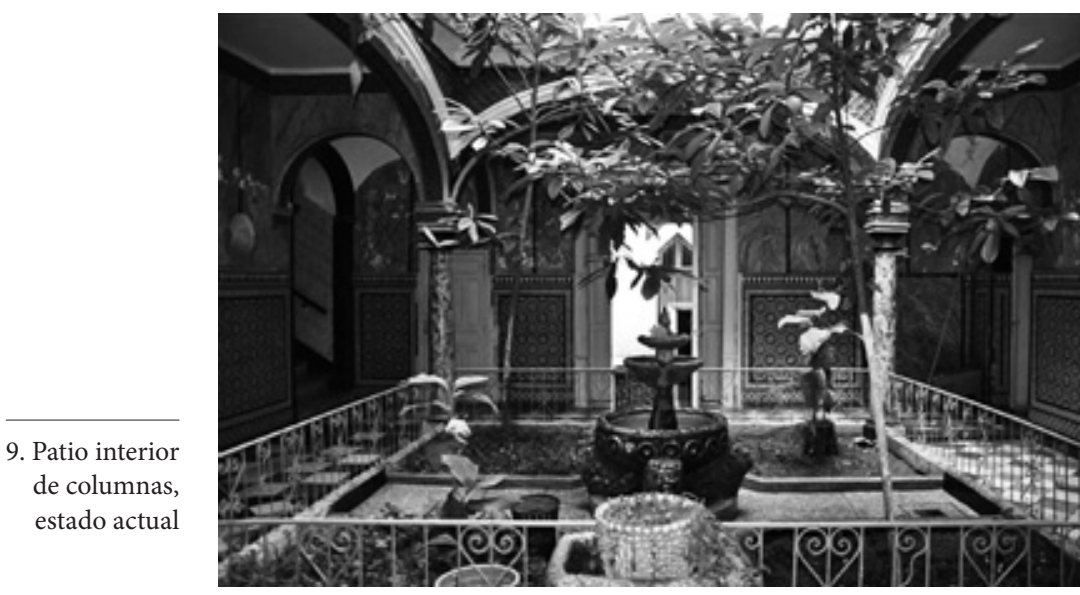

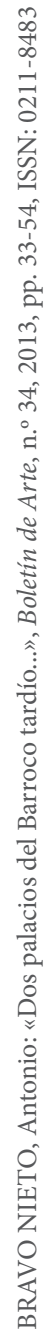
escalera, estado actual

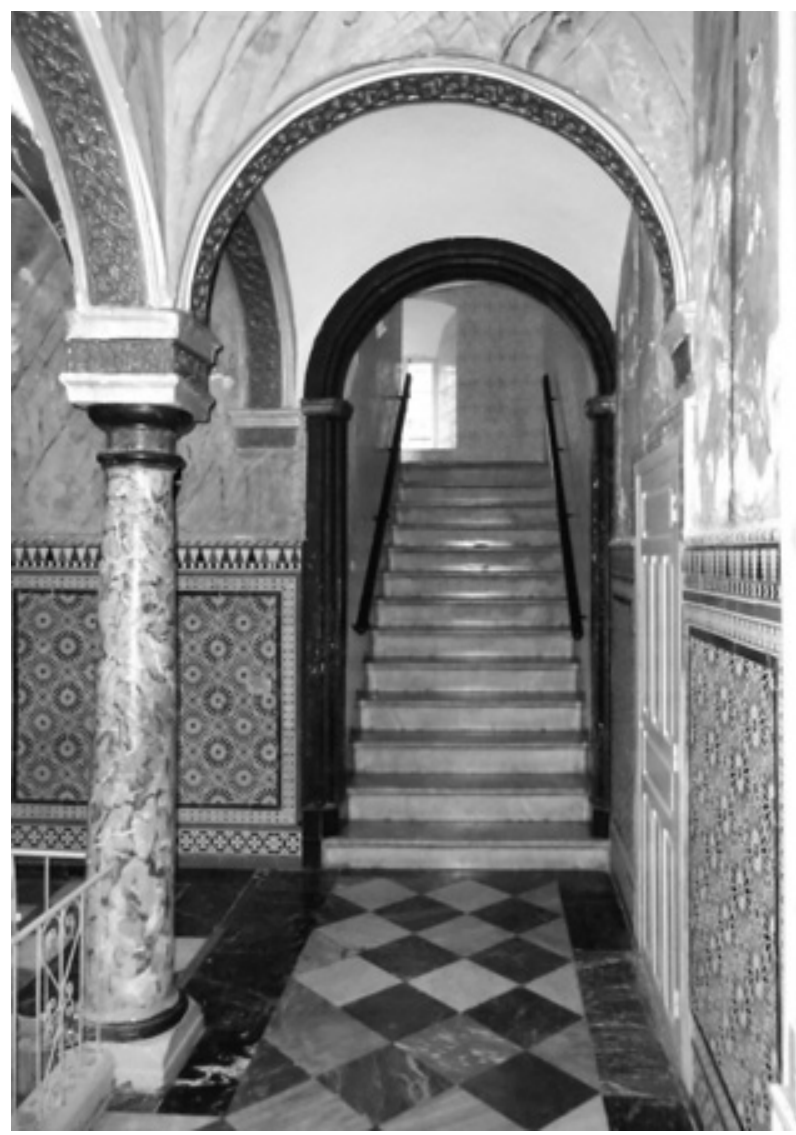

10. Columna y 
estuco, mientras que las arcadas muestran ornamentación tanto en su dovelaje en tono negro, como en su intradós y enjutas con motivos de yesería en sebka ${ }^{32}$. En el mismo patio, las entradas a las habitaciones que están situadas en el eje del crucero, presentan una portada ornamental con frontón recto, subrayando que se trataba de cuatro habitaciones o estancias destacadas.

En un lateral se abre la escalera, de mármol, que presenta en todo su desarrollo una cubierta formada por bóvedas de arista [10]. En la planta superior la galería se mantiene pero con pilares prismáticos. Este patio, al menos durante los primeros años del siglo $\mathrm{XX}$, fue cubierto para generar un amplio espacio superior que era utilizado para los grandes actos públicos de la Legación ${ }^{33}$, pero posteriormente se recuperó el patio abierto.

Las formas diseñadas a finales del siglo XVIII siguen estando presentes en este edificio, que pasó de ser el reflejo del interés diplomático de la política española en Marruecos a un uso actual más modesto, que no debiera impedir que en el futuro recupere una función más acorde con la finalidad para la que fue construido.

32 Nadia Erzini ya había señalado la integración que se produce en este edificio entre la estética barroca y los detalles ornamentales arabizantes.

33 Así lo encontramos en una fotografía de principios del siglo XX. ESPAÑA, Alberto, La pequeña historia de Tánger, Tánger, Distribuciones Ibérica, 1954, p. 42. 